Journal of The Magnetics Society of Japan Vol. 13, Supplement, No. S1 (1989)

(C) 1989 by The Magnetics Society of Japan

\title{
HIGH DENSITY VIDEO RECORDING EXPERIMENTS
}

\author{
Masataka ASHIKAWA, Shuuji OGASAWARA, Naoyuki SATO and Hidefumi FUNAKI
}

R \& D Laboratory, Tokin Corporation, 6-7-1, Kohriyama, Sendai 982, JAPAN

\begin{abstract}
A highly durable magnetic head for perpendicular magnetic recording was developed. Using this head, the research on a high resolution still-video picture recording system was performed. The developed head is a main-pole driven type head with a slider made of $\mathrm{ZrO}_{2}$ system material. The durability of this head for pass wear was over $2 \times 107$ passes for a $\mathrm{Co}-\mathrm{Cr} / \mathrm{Ni}-\mathrm{Fe}$ double layer medium. Using this head, a D50 over $110 \mathrm{kFRPI}$ was obtained. A video recording system was constructed for a trial, in which a carrier frequency was raised to $7.5 \mathrm{MHz}$, and a frequency deviation was extended to $2.5 \mathrm{MHz}$. The developed perpendicular head and the double layer disk was loaded in this system. Finally, we have successfully performed high-quality and high resolution frequency modulation video recording of still-pictures at highest recording density of 80kFRPI. The estimated number of horizontal line of the reproduced picture was about 600 .
\end{abstract}

\section{INTRODUCTION}

According to the recent increase of information which should be stored, the demand imposed on the recording system, that is to raise the recording density and increase the storage capacity, is emphasized year by year. Perpendicular magnetic recording is a promising technology to meet this demand. In order to make perpendiuclar recording practicable, not only the improvement of recording and reproducing performance at high densities but also the ensurrance of the pass wear durability related to the tribology between a head and a metalic thin film medium is an important research subject.

In order to realize perpendicular magnetic recording system, we have developed a highly durable main-pole driven type perpendicular head with a $\mathrm{Co}-\mathrm{Zr}-\mathrm{Nb}$ amorphous main-pole. Using this head and a $\mathrm{Co}-\mathrm{Cr} / \mathrm{Ni}-\mathrm{Fe}$ double layer medium, fundamental recording and reproducing performances were measured. Additonally, we have designed and constructed a video recording system, and tried video recording of color still-pictures.

This paper describes the outlines of the development of our perpendicular head and the experimental results of recording and reproducing characteristics measured using this head. The experimental results of video recording are also reported.

\section{PERPENDICULAR MAGNETIC HEAD}

Magnetic head

The structure of this head is illustrated in figure 1. Photo 1 shows the overview and the ferrite core of the head. The specifications of the head is shown in table 1. This head consists of a main-pole part which is made of $\mathrm{Co}-\mathrm{Zr}-\mathrm{Nb}$ amorphous sof $\mathrm{t}$ magnetic thin film which generates the magnetic field outside in recording and picks up the stray flux from the medium in reproduction, a coil part which excites the main-pole, a side core made of ferrite which plays a role of return path core, and a non-magnetic slider part which contacts with medium surface.

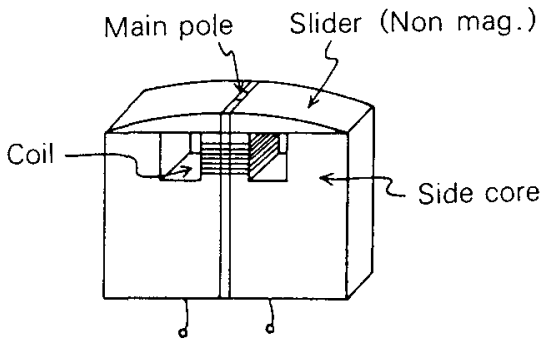

Fig.1 Structure of developed perpendicular magnetic recording head. 
In the development of the head, we have especially focused on selection of the slider material which contacts the medium and affects the durability.

Non-magnetic material for slider

When a magnetic head contacts a disk medium rotating at a high speed of $3600 \mathrm{rpm}$, the nonmagnetic material used for a head slider influences the head/media durability very much. Therefore, the selection of a nonmagnetic slider material is very important. In the fabrication process of the head, there are many process such as grass bonding of the soft magnetic ferrite core and sputtering of main-pole film on the slider substrate. In these process, many problems exist in mechanical strength, adhesive strength and magnetic properties. Hence the slider material should be selected from the

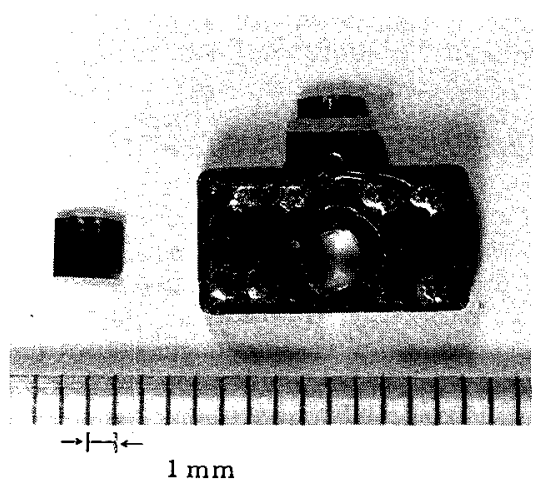

Photo 1 Magnetic head core and overview of magnetic head.

Table 1 Specifications of magnetic head.

\begin{tabular}{c|c|c}
\hline & Material & \multicolumn{1}{c}{$\begin{array}{l}\text { Co-Zr-Nb } \\
\text { a morphous }\end{array}$} \\
\cline { 2 - 3 } & Thickness & $0.25 \mu \mathrm{m}$ \\
\cline { 2 - 3 } & $\mathrm{Hc}$ & $0.07 \mathrm{Oe}$ \\
\cline { 2 - 3 } & $\mathrm{Bs}$ & 14000 gauss \\
\cline { 2 - 3 } & $\mu \mathrm{i}$ & 2000 \\
\hline Track width & $100 \mu \mathrm{m}$ \\
\hline
\end{tabular}

view points of thermal expansion, reactivity, magnetic property, etc.

The four candidates for a head slider material remained after pre-selection. They were: $\mathrm{A}: \mathrm{CaTiO}_{3}$ system, $\mathrm{B}: \mathrm{ZrO}_{2}$ system, $\mathrm{C}: \mathrm{ZnFe}_{2} \mathrm{O}_{4}$ system, and D:grass system. Among them, thermal expansion, hardness, tenacity, reactivity with grass, etc, are different. The perpendicular heads with the slider made of these four kinds of material were fabricated for a trial, and durability for $\mathrm{Co}-\mathrm{Cr} / \mathrm{Ni}-\mathrm{Fe}$ double layer medium was tested. The specification of this medium is listed in table 2 . In figure 2, the reproduced output voltage is plotted versus the number of pass after head loading. In this measurement, head/medium relative speed was $3600 \mathrm{rpm}$ (i.e. $7.2 \mathrm{~m} / \mathrm{s}$ in velocity). For the heads with $\mathrm{CaTiO}_{3}$ system, $\mathrm{ZnFe}_{2} \mathrm{O}_{4}$ system and grass system slider, the reproduced voltage becomes zero after 290 thousands, 690 thousands and 4 million passes, respectively. However, for the head with the $\mathrm{ZrO}_{2}$ system slider, the reproduced voltage after 20 million passes kept the almost same value as the original.

In course of this experiment, It was observed that once the scratches are caused on the surface of the head or the medium, the other is also scratched, and that when scraped powders of the head or the medium are caught in the spacing between head and medium, the possibility of occurrence of scratches is increases.

From the results of the durability test, we concluded that the perpendicular head with the $\mathrm{ZrO}_{2}$ system slider has a highest durability.

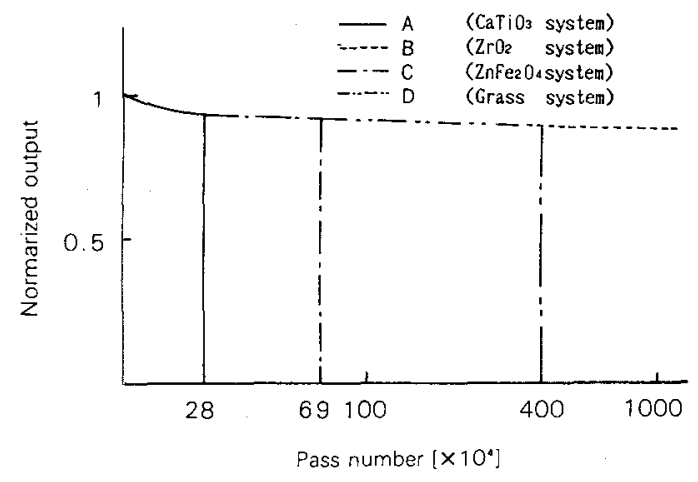

Fig.2 Durability test of magnetic heads. 


\section{RECORDING AND REPRODUCING CHARACTERISTICS}

\section{Measurement}

The recording and reproducing characteristics was measured with the developed perpendicular head explained above and the 2-in. $\mathrm{Co}-\mathrm{Cr} / \mathrm{Ni}-\mathrm{Fe}$ double layer flexible disk prepared by our company. The disk medium was rotated at $3600 \mathrm{rpm}(7.2 \mathrm{~m} / \mathrm{s}$ in speed). The specification of the medium is shown in table 2.

Recording density characteristics and Reproduced voltage vs. magneto-motive-force characteristics

Figure 3 shows the recording density characteristics and reproduced voltage vs. magneto-motive-force characteristics meas-

Table 2 Specifications of $\mathrm{Co}-\mathrm{Cr} / \mathrm{Ni}-\mathrm{Fe}$ double layer media.

\begin{tabular}{l|l|c|c}
\hline \multicolumn{2}{c|}{ Items } & Co-Cr & Ni-Fe \\
\hline \multirow{2}{*}{$\begin{array}{l}\text { Magnetic } \\
\text { layer }\end{array}$} & Thickness $(\mu \mathrm{m})$ & 0.18 & 0.5 \\
\cline { 2 - 4 } & $\mathrm{Hc}(\mathrm{Oe})$ & 800 & 0.5 \\
\cline { 2 - 4 } & $\mathrm{Ms}(\mathrm{emu} / \mathrm{cc})$ & 400 & - \\
\hline Disk diameter & \multicolumn{2}{|c}{$47 \mathrm{~mm}$} \\
\hline Protective layer thickness & $100 \AA, 200 \AA, 300 \AA$ \\
\hline
\end{tabular}

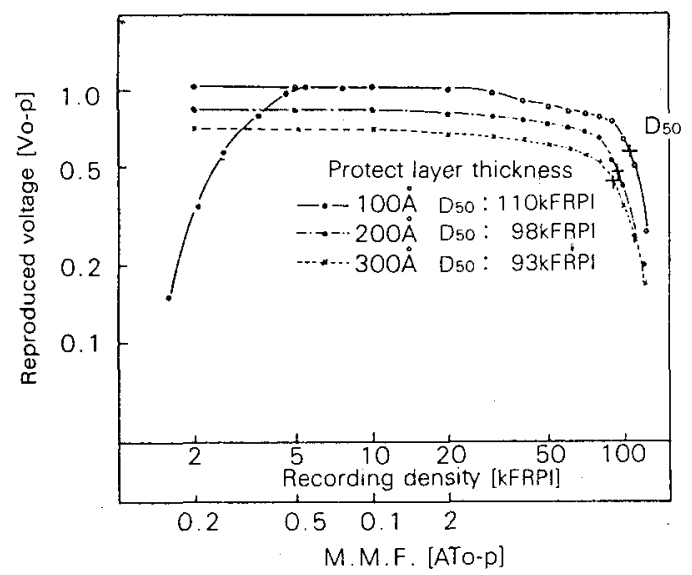

Fig.3 Reproduced voltage vs. recording density curves and reproduced voltage vs. recording magneto-motive-force curve. ured using the media with the protective layer of $100 \mathrm{~A}, 200 \mathrm{~A}$ and $300 \mathrm{~A}$ in thickness. For all media, the recording density of D50 exceeds 90kFRPI, where D50 is defined as the recording density at which the reproduced voltage becomes to a half value of that at low density of $2 \mathrm{kFRPI}$. Especially for the medium with $100 \mathrm{~A}$ thick protective layer, the D50 over 110kFRPI was achieved. From these results, it was expected that recording and reproduction is practically feasible at higher frequency over $15 \mathrm{MHz}$ in recording frequency.

In the reproduced voltage vs. recording magneto-motive-force curve, the NI90 which is a magneto-motive-force giving the $90 \%$ of the maximum reproduced voltage is less than $0.4 \mathrm{AT}_{\mathrm{O}-\mathrm{p}}$ for all media. This shows that the

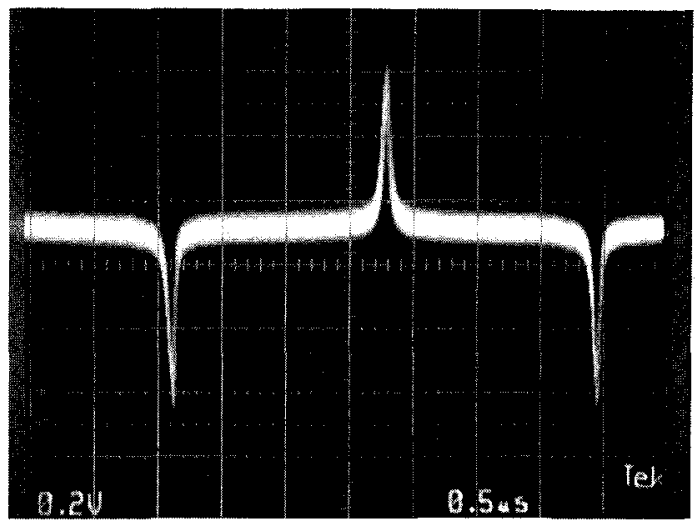

Photo 2 Reproduced pulses for isolated magnetization transitions at $2 \mathrm{kFRPI}$.

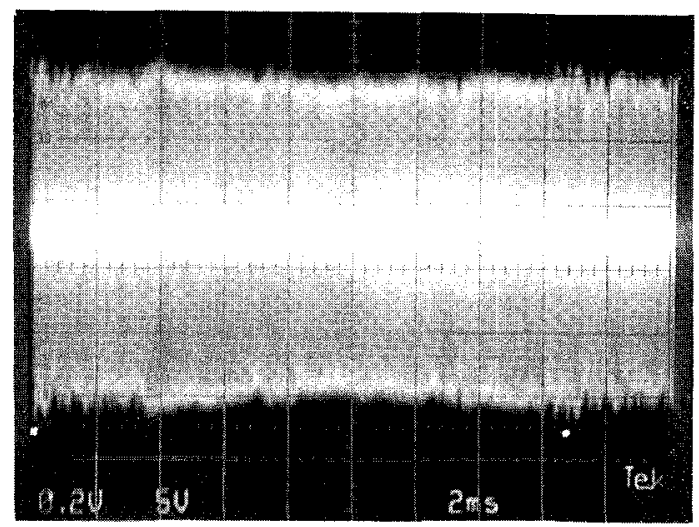

Photo 3 Reproduced envelope at 10kFRPI. 
recording sensitivity is sufficiently good. The reproduced voltage at the head terminal combined with the medium with a $100 \mathrm{~A}$ thick protective layer was $700 \mathrm{uV}$. The reproduced voltage at $10 \mathrm{kFRPI}$ normalized by the trackwidth, number of turns and velocity was $50 \mathrm{nV}$ o-p.

The reproduced pulse shape for the isolated magnetization transition at $2 \mathrm{kFRPI}$ and the envelope of the reproduced voltage at $10 \mathrm{kFRPI}$ for the medium with a $100 \AA$ thick protective layer are shown in photo 2 and photo 3 , respectively.

As described above, in the combination of our head and medium, the recording and reproducing sensitivity is good enough to perform recording and reproducing at high frequency. Hence we have constructed a high resolution video recording system with a extended video signal band, and tried video recording.

\section{VIDEO RECORDING EXPERIMENTS}

\section{Experimental Setup}

Figure 4 shows the block diagram of the apparatus used for the recording and reproducing experiments of high resolution still-picture. Table 3 shows the main specifications of the video recording system. This system is composed of a mechanical unit, a video signal processing unit, a S-RGB converter unit, a synchronized signal processing unit and a IC memory unit. The mechanical unit has a spindle motor to rotate the disk medium and a head suspension arms. The video signal processing unit has a modulator which converts NTSC signal to recording signal and a demodulator. In the S-RGB converter unit, the reproduced signal is converted to RGB signal. The synchronized signal processing unit, the reproduced signal is synchronized with a clock signal in a IC video signal memory. The IC memory is composed of the $A / D$ and $D / A$ converters, memory and a personal computer. A video signal from a camera is converted to recording signal in the video signal processing unit, and recorded on a magnetic disk by a magnetic head. On the magnetic disk, one frame of video signal is divided into two tracks. One field is recorded on one track. In reproduction, the reproduced signal from each track is synthesized into one frame in a IC memory.

Table 3 Specifications of video recording system.

\begin{tabular}{l|l}
\hline Revolutions per minute & $3600 \mathrm{rpm}$ \\
\hline Medium & 2 inch flexible disk \\
\hline Recording form & 1 field/1 track \\
\hline
\end{tabular}

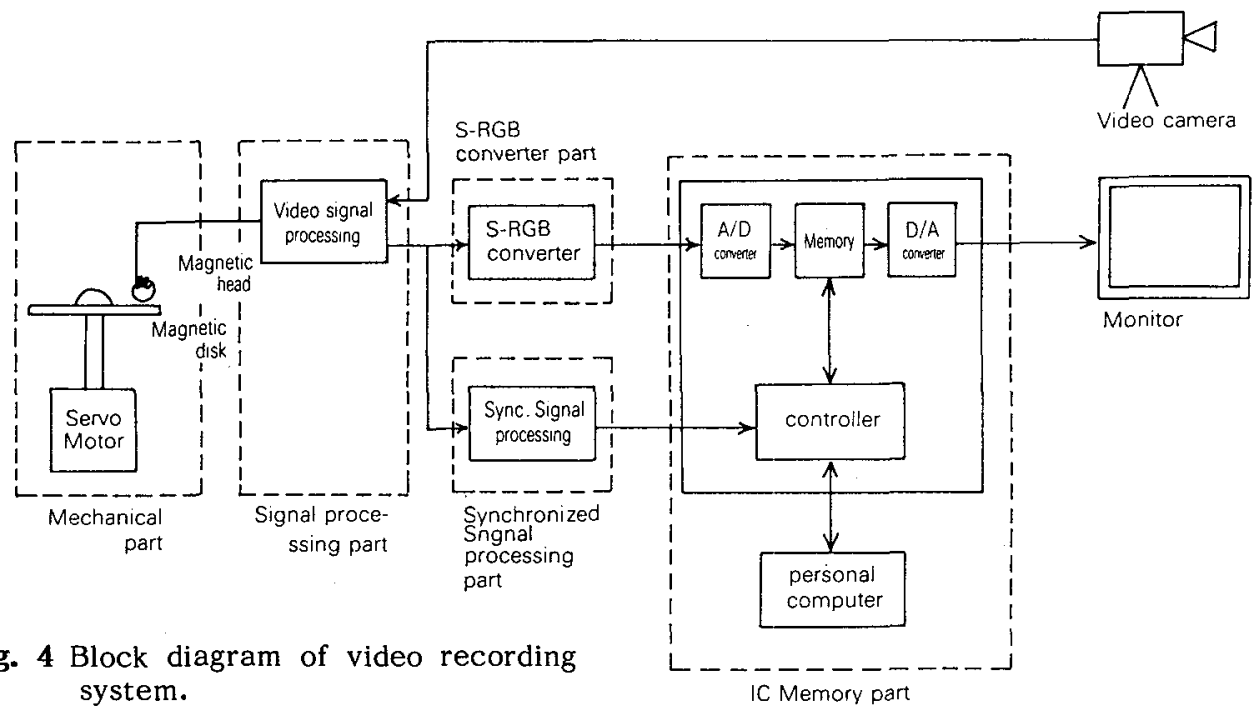


We predicted that the recording of a wide band video signal is possible from the recording and reproducing characteristics measured using the perpendicular magnetic head and a disk medium. Thus we have performed the experiment of high resolution still-picture recording in which the horizontal resolution is neearly equivalent to 600 lines. In this experiment, a upper frequency limit for luminance signal is expanded to $7.5 \mathrm{MHz}$.

Video signal processing unit

Many recording method of the video signal was investigated so far. Some of them are used in a VCR. In order to improve the horizontal resolution, band width of the luminance signal should be extended to $7.5 \mathrm{MHz}$, and the carrier frequency should be raised in the video recording experiment.

(a) Separated $\mathrm{Y} / \mathrm{C}$ input and output

In our system, in the channel from the camera to the input of the video recording system, Y-signal and C-signal are transmitted separately. And the demodulated $Y$-signal and C-signal are also amplified separately to decrease the degradation of vertical resolution.

(b) Recording method

In figure 5, the block diagram of the signal processing unit is shown. $Y$-signal is mixed with a synchronized signal and is modulated with low frequency carrier in frequency modulation. On the other hand, C-signal is separated to two signals (R-Y and $B-Y$ signal) in the decoder, and they are modulated by frequency modulation. Frequency modulated chrominance signal is converted to low frequency band in the converter, and is mixed with the frequency modulated $Y$-signal to recording signal. The disk medium rotates at $3600 \mathrm{rpm}$. NTSC signal of one field (which is $1 / 60 \mathrm{sec}$ ) is recorded on one track of the medium. In the reproduction, the flow direction of the signal is opposite to that in recording. That is, the signal reproduced by the head is separated to $Y$-signal and chrominance signal by a filter. Succeedingly, Y-signal component is demodulated and the chrominance signal is converted, demodulated and separated to RY, B-Y chrominance signals. These two chrominance signals is converted to C-signal in encoder, and is output with Y-signal. (c) Recording format

- In frequency modulation, when a carrier frequency is raised, a lower sideband can be spread more, and a wider band video signal becomes available. This widening of video band contributes to the improvement of a horizontal resolution.

In our experiments, D50 over $110 \mathrm{kFRPI}$ was obtained at head-medium relative speed of $7.2 \mathrm{~m} / \mathrm{s}$. In other words, recording and reproduction of signal over $15 \mathrm{MHz}$ was possible. Hence it seems to be possible to raise the carrier frequency to $10 \mathrm{MHz}$. Figure 6 shows a video signal frequency allocation of the video recording system used in our experiment. If only the carrier frequency is raised, as the upper sideband width is restricted, the reversing phenomena easily occurs, and sometimes the quality of reproduced picture is degraded because of low $\mathrm{S} / \mathrm{N}$. Hence in this experiment, frequency deviation which affects to $S / N$ of the luminance signal was extended to $2.5 \mathrm{MHz}$.

As the result, we have succeeded in improvement of resolution by setting a highest frequency of luminance to $7.5 \mathrm{MHz}$ without degradation of quality of a picture. By the wide band width, the high horizontal resolution close to 600 lines was realized.

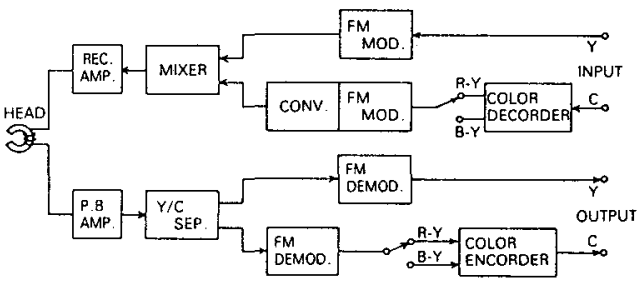

Fig. 5 Block diagram of video signal processing.

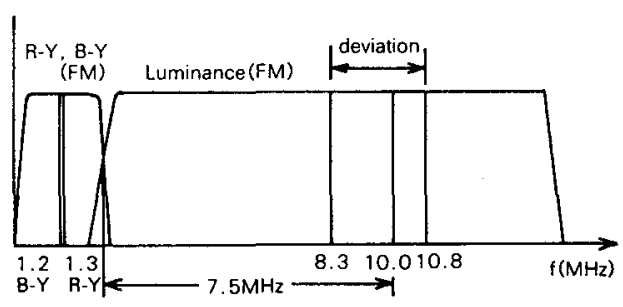

Fig. 6 Frequency allocation of video recording system. 
Results of video recording experiments

Finally, the video recording experiments of a still picture was performed in the video recording system. The shortest recording wavelength of the carrier was $0.63 \mathrm{um}$, and the highest recording density was $80 \mathrm{kFRPI}$.

An example of the reproduced pictures is shown in photo 4 .

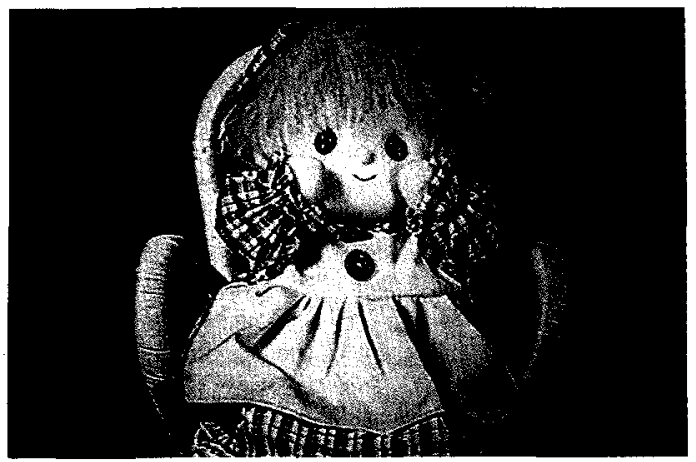

Photo 4 An example of reproduced pictures.

\section{CONCLUSIONS}

The highly durable main-pole driven type perpendicular head was developed by introducing the $\mathrm{ZrO}_{2}$ system material for the head slider. And the 2-in flexible video recording system using this head was constructed to try high resolution video recording. The obtained results are as follows:

(a) It was found that the perpendicular head with the $\mathrm{ZrO}_{2}$ system slider has the durability surpassing 20 million passes.

(b) The D50 over 110kFRPI was obtained using the perpendicular head with $0.25 \mathrm{um}$ thick main-pole and the $\mathrm{Co}-\mathrm{Cr} / \mathrm{Ni}-\mathrm{Fe}$ double layer medium at the disk revolution of 3600 rpm. The corresponding recording frequency was $15.5 \mathrm{MHz}$.

(c) It was confirmed that the high-quality and high-resolution recording of the color still-picture was possible. The horizontal resolution of the reproduced picture was estimated at about 600 lines.

However, from the practical viewpoints, some problems still remain in the technologies to maintain the small head-tomedium spacing stably and to realize higher durability of head and media. We intend to continue making more effort to improve the quality of video recording.

We would like to express our appreciation to professor S.IWASAKI, professor Y.NAKAMURA, their members in the research institute of electrical communication, Tohoku university, and Dr. T.OKADA of head manager in $R$ \& $D$ Laboratory of Tokin corporation, for their helpful guidance and encouragement.

\section{REFERENCES}

[1] S.IWASAKI and K.TAKEMURA, Natl. Conv. Rec. IEICE Japan, 17-1 (1974).

[2] S.YAMAMOTO, Y.NAKAMURA and S.IWASAKI, Journal of Magnetics Society of Japan, Vol.11, No.2, pp. 109 (1987).

[3] S.IWASAKI and Y.NAKAMURA, Journal of Inst. of Television Enginners of Japan, Vol.18, No.10 (1964).

[4] S.IWASAKI and K.TAKEMURA, IEEE Trans. Magn., Vol.MAG-11, No.5, pp.1173 (1975).

[5] S.IWASAKI and K.OUCHI, IEEE Trans. Magn., Vol.MAG-14, No.5, pp.849 (1978).

[6] J.NUMAZAWA, Y.YONEDA and S.NAKAGAWA, Report of Technical Group on Magnetic Recording, MR84-11, pp.47 (1984)

[7] T.OZUE, I.SAITO, K.TAKAHASHI, T.NARAHARA, K.KAWAZOE and J.HOKKYO, Report of Technical Group on Magnetic Recording, MR84-53, pp. 43 (1984).

[8] Y.YONEDA, J.NUMAZAWA and K.YOKOYAMA, Report of Technical Group on Magnetic Recording, MR82-20, pp. 15 (1985). 